\title{
DIFFERENTIATION FACTORS THAT INFLUENCE NEURONAL MARKERS EXPRESSION IN VITRO FROM HUMAN AMNIOTIC EPITHELIAL CELLS
}

\author{
Hassan Niknejad ${ }^{1,2, *}$, Habibollah Peirovi ${ }^{1}$, Abolhassan Ahmadiani², Jalal Ghanavi ${ }^{3}$, and Masoumeh Jorjani ${ }^{1,2}$ \\ ${ }^{1}$ Nanomedicine and Tissue Engineering Research Center, \\ ${ }^{2}$ Department of Pharmacology and Neuroscience Research Center, Faculty of Medicine, \\ ${ }^{3}$ Animal Research Laboratory, NRITLD, Masih Daneshvari Hospital, Shaheed Beheshti Medical University, \\ Darabad, Tehran, Iran
}

\begin{abstract}
The differentiation of neural cells from embryonic stem cells is influenced by several growth factors. Amniotic epithelial cells (AECs) share many of the same characteristics as embryonic stem cells, and therefore those factors may similarly affect the derivation of neural cells from AECs. In this study, we examined the differentiation of neural cells in vitro from AECs following AECs treatment with retinoic acid (RA), basic fibroblast growth factor (bFGF) as well as investigation of bFGF withdrawal on neuronal differentiation. We also studied whether blocking bone morphogenetic protein (BMP) signaling using its antagonist, noggin, affects the derivation of neuronal cells from AECs. The effects of serum on the rate of neural markers expression were also examined. Analysis of AECs derived neurons was performed at some neural markers expression level by immunocytochemistry. All cultures treated with noggin showed the higher levels of neural markers expression than noggin free cultures. Combined treatment with bFGF and RA showed the highest level of neural markers in all treatment groups with or without noggin. bFGF withdrawal did not promote expression of neural markers, while its maintenance increased the expression of these markers. Serum-free condition decreased the viability of cells but increased the rate of neural markers expression. These results show the capability of AECs to express neural cell markers and this ability is affected by some factors including serum, noggin, bFGF and RA.
\end{abstract}

Keywords: Amniotic epithelial cells, noggin, basic fibroblast growth factor (bFGF), retinoic acid, serum, neuronal markers.

*Address for correspondence

Hassan Niknejad

Nanomedicine and Tissue Engineering Research Center

Shaheed Beheshti Medical University

P.O. Box 1985711151, Tehran, Iran

Telephone Number: +98-21 22439847

FAX Number: +98-21 22439848

E-mail: niknejad@sbmu.ac.ir

\section{Introduction}

The nervous system is a stimulating target for regenerative medicine. Since direct regeneration of brain tissues is difficult to achieve, an alternate supply of neural cells is required in order to attain any therapeutic goal. Recent progress in stem cell biology has led to new approaches to the generation of neurons. One interesting approach is the use of embryonic stem cells (ESCs). ESCs are capable of unlimited cell expansion in vitro while maintaining their pluripotency. In spite of the many advantages of ESCs, they have limitations for use in a clinical setting. The major restrictions of ESCs include tumorgenicity, immunological state and complex ethical issues. These issues are the major motivation underlying the search for alternative sources (Niknejad et al., 2008).

Amniotic epithelial cells (AECs) that are obtained from the innermost layer of the amniotic membrane (AM) have several characteristics that make them an excellent alternative for ESCs. Recent studies aimed at defining the stem cell-like characteristics of AECs show that these cells express the surface markers normally associated with ESCs, e.g. SSEA (stage-specific embryonic antigen)-3, SSEA-4, TRA (tumor rejection antigen)-1-60, and TRA1-81. These cells also express pluripotent stem cellspecific transcription factors such as Oct-4 and Nanog (Miki et al., 2005; Miki et al., 2007). Though AECs are pluripotent, these cells do not form teratomas upon transplantation into the testes of SCID mice (Ilancheran et al., 2007, Miyamoto et al., 2004). It has been also shown that AECs have low immunogenicity and would therefore have a reduced risk of rejection upon transplantation (Niknejad et al., 2008). In addition, the AM is discarded after Cesarean section, and its use bypasses the ethical controversy of manipulating human ESCs. Overall, these characteristics of AECs make them an excellent source of functional differentiated cells for cell replacement therapy, provided that reliable means of inducing differentiation to specific cell types can be achieved.

Neural differentiation of ESCs based on serum omission and basic fibroblast growth factor (bFGF) withdrawal with some modifications was used as a pattern for current research. The neural cell differentiation pattern of ESCs is also significantly influenced by differentiation factors such as retinoic acid (RA) and bFGF. RA plays a fundamental role in the development of the central nervous system, stimulating outgrowth and migration of the neural crest (Maden and Holder, 1992). bFGF is highly expressed in the nervous system and is required for normal cortex development (Dono et al., 1998). It has been shown that 


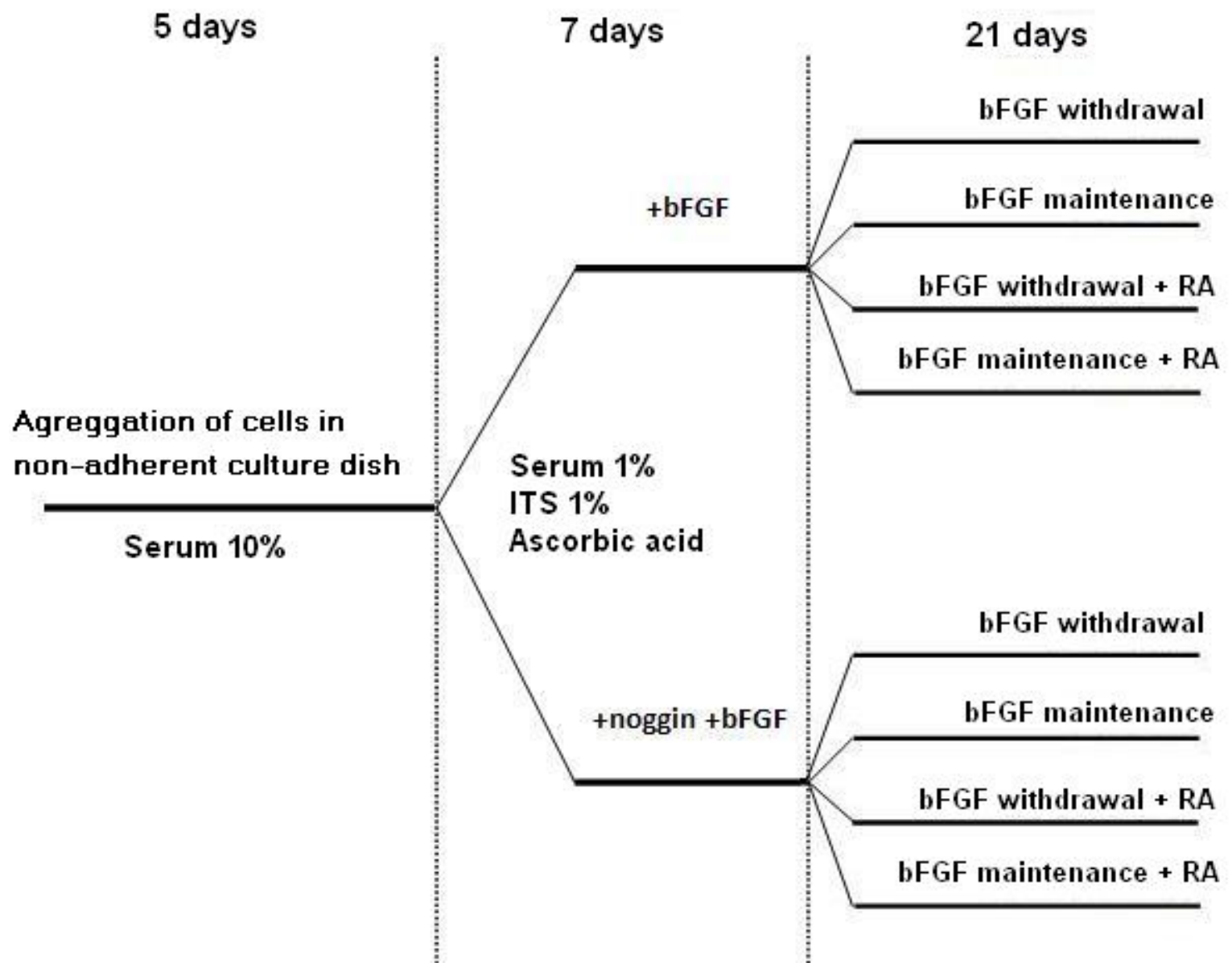

Figure 1. Schematic of the differentiation protocol of AECs to neural marker- positive cells in the present study and various experimental groups.

interaction between bFGF and RA is a critical determinant for neural differentiation (Mao and Lee, 2005).

Other factors are also used for neural differentiation of stem cells. Some neural inducers have been shown to act by antagonizing bone morphogenetic protein (BMP). It has been reported that BMP2 plays a critical role in ESC differentiation to extraembryonic endoderm (Pera et al., 2004) and inhibits neuroectoderm differentiation (Tropepe et al., 2001; Ying et al., 2003). On the other hand, in Xenopus, BMP4 inhibits neural differentiation of animal cap ectoderm and promotes epidermogenesis (Sasai et al., 1995; Wilson and Hemmati-Brivanlou, 1995). Since AECs are potentially susceptible to give rise to a wide variety of cells other than neural cells, we investigated whether blocking BMP signaling using its antagonist noggin affects the derivation of neural cells from AECs. Hence, the aim of this study was to investigate the ability of neural cell markers expression on human AECs with various supplements under culture conditions.

\section{Materials and Methods}

\section{Isolation of AECs}

Human AM was prepared using fresh human placenta $(n=11)$ according to the methods previously described by Miki et al. (2005) with the following modifications. All procedures were performed under sterile conditions. The placentas were obtained immediately after elective Cesarean sections with normal gestation, Immersed in phosphate-buffered saline (PBS, Sigma, St. Louis, MO, USA) containing $50 \mu \mathrm{g} / \mathrm{ml}$ penicillin, $50 \mu \mathrm{g} / \mathrm{ml}$ streptomycin, $100 \mu \mathrm{g} / \mathrm{ml}$ neomycin, and $2.5 \mu \mathrm{g} / \mathrm{ml}$ amphotericin $\mathrm{B}$. The amnion was mechanically peeled of the chorion and washed several times with PBS. To release AECs, the AM was incubated at $37^{\circ} \mathrm{C}$ with $0.15 \%$ trypsinEDTA. Cells from the first 10 minutes of digestion were discarded to exclude debris. The solutions from the second and third 40-minute digests were pooled. Trypsin was inactivated with fetal calf serum (FCS) and the solution was centrifuged at $2500 \mathrm{rpm}$ for $12 \mathrm{~min}$. Cells were washed with PBS and suspended in Dulbecco Modified Eagle's Medium (DMED)/F12 containing $100 \mathrm{U} / \mathrm{ml}$ penicillin/ streptomycin solution and $10 \%$ FCS. Viability of AECs was determined by exclusion of trypan blue dye. The purity of the isolates was determined by immunostaining with the epithelial marker pan-cytokeratin.

\section{Differentiation protocol}

AECs were seeded on tissue culture plates at a density of $8-10 \times 10^{4}$ cells per $\mathrm{cm}^{2}$ in the aforementioned medium containing $10 \mathrm{ng} / \mathrm{ml}$ epidermal growth factor (EGF) supplemented with $2 \mathrm{mM}$ L-glutamine, $1 \%$ nonessential amino acids, $55 \mu \mathrm{M}$ 2-mercaptoethanol, $1 \mathrm{mM}$ sodium pyruvate. This medium was used as standard culture medium. Within 3 days, AECs achieved $>90 \%$ confluency, 

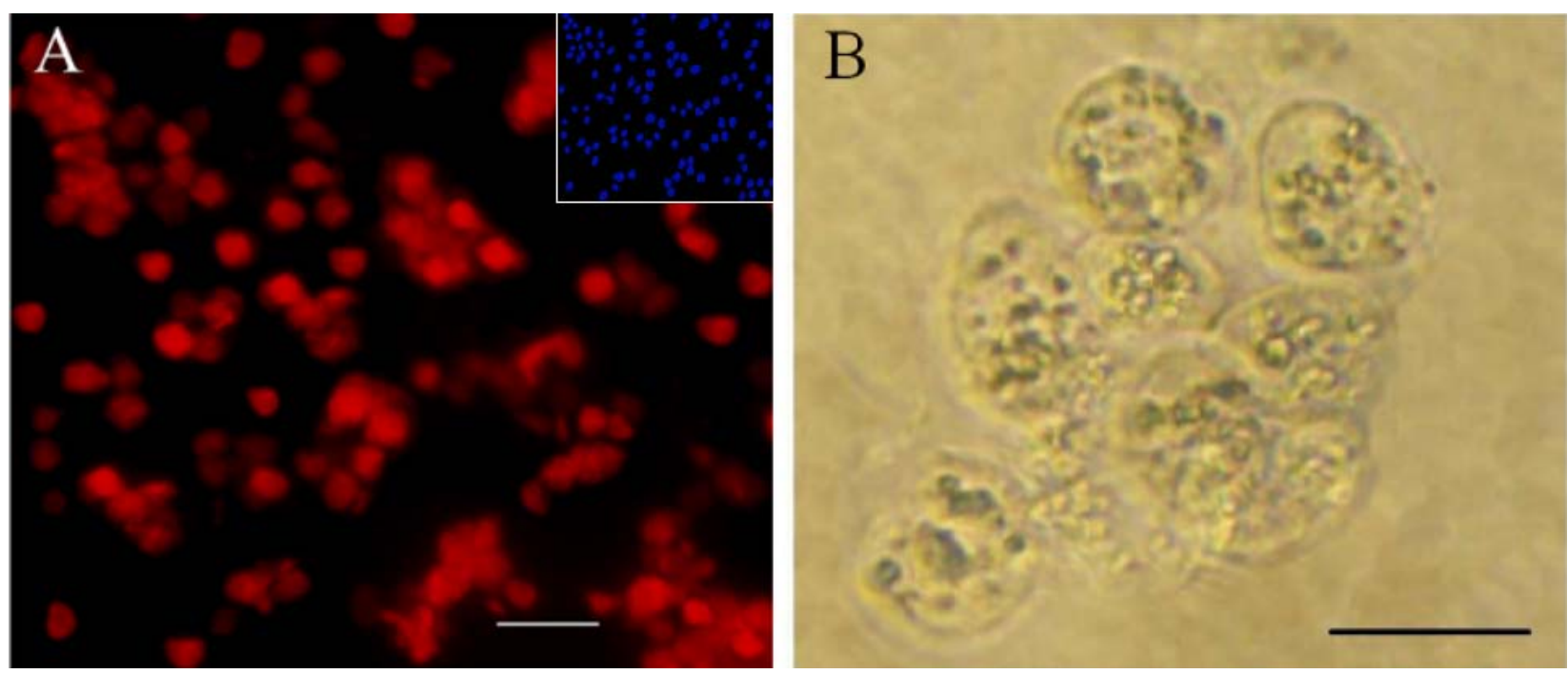

Figure 2. (A) Immunofluorescence detection of cytokeratins with rhodamine-conjugated secondary antibody in cultured AECs. The figure shows the epithelial characteristics of isolated cells. The inset shows DAPI nuclear staining of the same field. (B) Aggregation of AECs with high cell density for embryoid body formation in nonadherent bacteriological dishes. No sign of embryoid body was seen up to 10 days. Scale bars in both figures: 50 $\mu \mathrm{m}$.

and medium was removed for isolation of floating cells and the loosely attached cells were detached by incubation with $\mathrm{Ca}^{2+}-\mathrm{Mg}^{2+}$-free Hank's balanced salt solution (HBSS). All pooled cells were transferred to non-adherent bacteriological dishes and allowed to aggregate for 5 days. The aggregated cells were dissociated into single cells by gently pipetting and plated onto gelatin-coated dishes at a concentration of $2 \times 10^{4}$ cells per $\mathrm{cm}^{2}$. The standard medium was supplemented with $1 \%$ insulin/transferrin/selenium (ITS), $2 \mathrm{mM}$ ascorbic acid, 1\% FCS, $10 \mathrm{ng} / \mathrm{ml} \mathrm{bFGF}$ and the half of the cultures was supplemented with $100 \mathrm{ng} / \mathrm{ml}$ noggin. After culture for 7 days, for the final differentiation, in some cultures bFGF was removed and the cells were allowed to differentiate for 7, 14 and 21 days. During this period, some cultures were exposed to $1 \mu \mathrm{M}$ RA. The day of bFGF withdrawal was indicated as day 0 (D0). The schematic depiction of the differentiation protocol and various experimental groups are shown in Fig.1.

\section{Immunocytochemistry}

Characteristic analysis of AEC-derived neurons was performed at the protein expression level by immunocytochemistry. Cells were fixed at room temperature with $4 \%$ paraformaldehyde for 10 minutes, washed with PBS, and incubated with $10 \%$ goat serum and $0.1 \%$ Triton X-100 for 1 hour. The following primary antibodies were applied for immunocytochemistry: pancytokeratin (Sigma, 1:200), human $\beta$-tubulin III (Sigma, 1:100), Neuron-specific nuclear protein (NeuN; Chemicon, 1:100), Neuron specific enolase (NSE; Chemicon (now Millipore, Billerica, MA, USA), 1:100), GATA-6 (R\&D Systems, Minneapolis, MN, USA; 1:200), brachyury (Sigma, 1:200). The primary antibodies were applied and incubated overnight at $4^{\circ} \mathrm{C}$. Anti-rabbit and anti-mouse IgG secondry antibodies conjugated with rhodamine and fluorescein (Chemicon, 1:100) were applied for 30 minutes after washing with PBS. Isotype-matched rabbit or mouse
IgG at concentrations similar to specific antibodies were added as negative control in each experiment. The total number of cells was counted by staining nuclei with 4',6diamidino-2-phenylindole (DAPI)(Sigma).

\section{Statistical analysis}

The cells in 8-10 randomly selected fields were viewed at 200x magnification and the percentage (mean \pm standard error of the mean, SEM) of positively staining cells was calculated. The significance of the data was tested by oneway analysis of variance (ANOVA) followed by the Tukey post-test.

\section{Results}

\section{Morphology and characteristics of isolated cells}

The viability of isolated cells was more than $95 \%$, as detected with trypan blue. The viability was depending on the concentration of trypsin-EDTA, the period of incubation of tissue in trypsin-EDTA solution and the freshness of the placenta. The literature reports the use of trypsin-EDTA ranging from $0.02 \%$ to $0.25 \%$ for 10 minutes to 2 hours (Hopkinson et al., 2008). To achieve the desired viability, we examined the mentioned concentrations and times in other reports. Based on our previous results, $0.15 \%$ trypsin-EDTA and 40 minutes digestion ( 2 times) were the best conditions for isolation of AECs. Freshness of placenta was another determinant for the viability of isolated cells as the viability decreased to $75 \%$ at 24 hours post delivery (the tissue was maintained at $4^{\circ} \mathrm{C}$ ).

After 3 days in culture, two types of cells were observed. One type of cells floating in the medium or loosely attached to the culture dish with a round shape and another type of cells that firmly attached with a different morphological appearance. Since it has been 

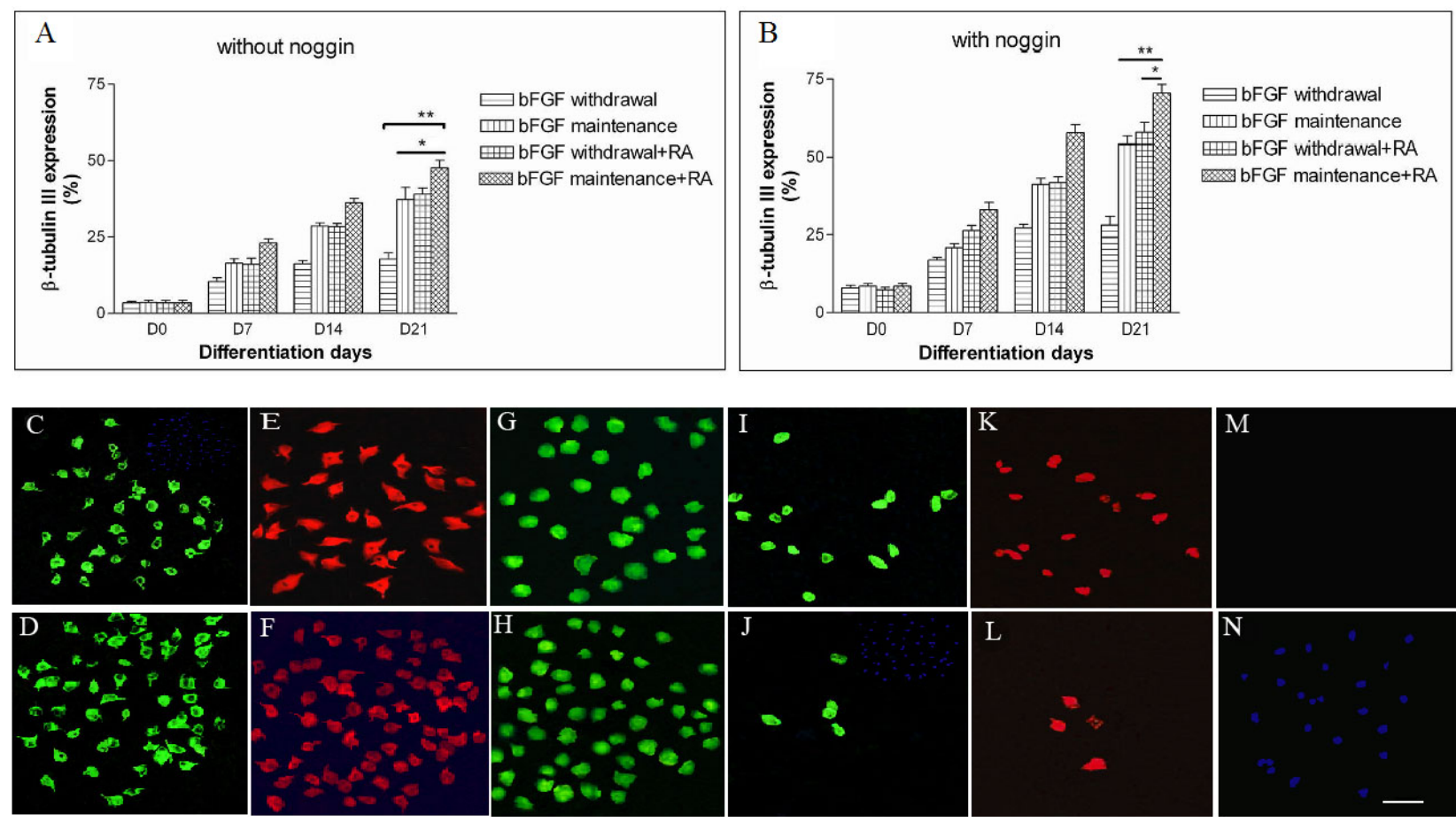

Figure 3. $\beta$-tubulin III expression from in vitro differentiated AECs, following bFGF withdrawal, its maintenance, RA, or combination of these treatments without noggin pretreatment (A) and with noggin pretreatment for 7 days (B). Data are presented as mean \pm SEM $(n=4)$ of six independent experiments. At day 21 , combined treatment with bFGF and RA (bFGF maintenance+RA) showed significantly higher levels of $\beta$-tubulin III antibody positive cells compared to the other treatment groups. (*) $P<0.05$; (**) $P<0.01$. (C-H) immunofluorescence staining for neural markers expression in vitro from differentiated AECs. Immunofluorescence detection of $\beta$-tubulin III, NSE and $\mathrm{NeuN}$ after treatment with $\mathrm{bFGF}+\mathrm{RA}$ for 21 days in noggin-free $(\mathbf{C}, \mathbf{E}$ and $\mathbf{G})$ and noggin-pretreated $(\mathbf{D}, \mathbf{F}$ and $\mathbf{H})$ groups. (I-L) immunofluorescence analyses for GATA-6 (endodermal marker) and brachyury (mesodermal marker) in bFGF maintenance+RA groups at D21. The numbers of GATA-6 and brachyury positive cells were increased in noggin-free cultures ( $\mathbf{I}$ and $\mathbf{K}$ ) in comparison to noggin-pretreated cultures ( $\mathbf{J}$ and $\mathbf{L}$ ). A representative IgG negative control is also shown (M). Panel N (negative control) and insets in panels C and J show DAPI nuclear staining of the same fields. Scale bars: $50 \mu \mathrm{m}$.

shown that the first type of cells possess stem cell markers (Miki et al., 2005), we isolated and used these cells in the present study. Approximately all isolated cells reacted with antibodies to pan-cytokeratins, confirming their epithelial nature and the lack of contamination with mesenchymal fibroblasts (Fig. 2A).

\section{Embryoid body formation was not observed by cell- cell contact}

For embryoid body formation, AECs were aggregated in bacteriological dishes at high cell density. In spite of the formation of clumps of 4-5 cells, no sign of embryoid body formation was observed up to 10 days (Fig. 2B), as reported in the ESC differentiation protocol (Lee et al., 2000; Park et al., 2004). Although embryoid bodies were not formed by aggregation of cells, this step was not omitted from our protocol. As mentioned, the next step was dissociation of aggregated cells into single cells and plating onto gelatincoated dishes. When AECs were plated onto gelatin-coated dishes without pre-aggregation, only a small number of cells (less than 5\%) adhered to the substrate after 4 hours and nearly $70 \%$ adhered after 3 days, while all cells after pre-aggregation adhered to the substrate after 4 hours. We conclude that cell aggregation during this step is important for the attachment of cells in the next step since single cells without pre-aggregation showed a very low attachment to gelatin-coated culture dishes.

\section{bFGF increases the expression of neural markers}

On day $0,3.5-4 \%$ and $7.5-8.5 \%$ of noggin-free and noggintreated cells were positive for $\beta$-tubulin III antibody, respectively. To investigate the effects of bFGF or its withdrawal on neural differentiation, bFGF was removed from half of the cultures. Investigation into the effects of bFGF in both the noggin-treated and the noggin-free groups showed a significant difference between bFGF withdrawal and bFGF maintenance at day 7 and thereafter $(P<0.05$ for D7 and $P<0.01$ for D14 and D21). At day 21 , rates of $\beta$-tubulin III expression for bFGF maintenance and $\mathrm{bFGF}$ withdrawal were $37.2 \pm 3.9 \%$ and $17.8 \pm 1.9 \%$ in the noggin-free group (Fig. $3 \mathrm{~A}$ ) and $54 \pm 2.6 \%$ and $28 \pm 2.9 \%$ in the noggin-treated group (Fig. 3B), respectively. These cells also expressed other neuronal markers. After 3 weeks of differentiation (D21), the number of $\mathrm{NSE}^{+}$and $\mathrm{NeuN}^{+}$ cells for bFGF maintenance were $35.1 \pm 2.8 \%$ and $33.5 \pm 3.2 \%$ in the noggin-free group and $57.2 \pm 5.1 \%$ and $55.9 \pm 3.8 \%$ in the noggin-treated group, respectively. With regard to $\beta$-tubulin III, higher levels of NSE and NeuN 


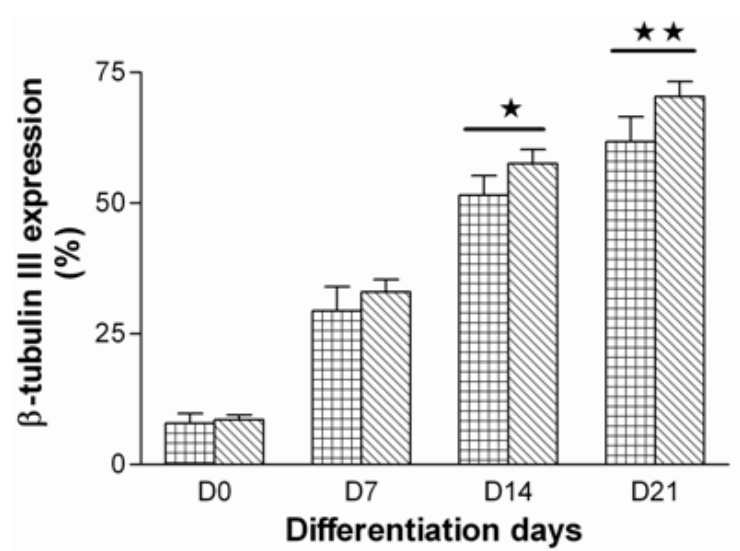

Serum $10 \%$

Serum $1 \%+$ ITS $1 \%$

Figure 4. the effects of the serum on in vitro $\beta$-tubulin III expression in AECs following differentiation with bFGF maintenance+RA and pretreatment with noggin. In half of the cultures, $1 \%$ ITS was added and the serum was decreased to $1 \%$ and compared with cultures with serum $10 \%$. Data are presented as mean $\pm \operatorname{SEM}(\mathrm{n}=4)$ of six independent experiments. At day 14 and day 21 , the treatment with $1 \%$ serum $+1 \%$ ITS showed significantly higher levels of $\beta$-tubulin III antibody positive cells compared to the $10 \%$ serum groups. $(*) P<0.05$; (**) $P<0.01$. expression were observed after bFGF maintenance in comparison to bFGF withdrawal.

\section{EGF is an essential factor for survival of AECs}

EGF was another mitogen and survival factor used in this study. In some studies, EGF withdrawal has been used as an inducer of neuronal cells from stem cells. In order to assess the effect of EGF withdrawal on neural markers expression, EGF was omitted on D0. EGF omission decreased cell viability in all treated cultures (e.g., less than $10 \%$ in noggin-treated cultures), so its presence was essential for continuation of the experiments.

\section{RA treatment and bFGF maintenance similarly affect on expression of neural markers}

It has previously been shown that RA treatment of mouse ESCs in vitro induces a concentration-dependent and timedependent differentiation of neuronal cells (Guan et al., 2001). In these studies, RA was used as neurotrophic factor in some cultures contemporaneous with bFGF withdrawal. Addition of RA to the bFGF withdrawal group (bFGF withdrawal+RA) revealed similar levels of $\beta$-tubulin III expression when compared to the bFGF maintenance group in both noggin-treated and noggin-free groups, except that at day 7 in noggin-treated cultures the difference was significant $(P<0.05)$. At day 21 , bFGF withdrawal+RA treated cultures exhibited $57.8 \pm 3.2 \%$ of $\beta$-tubulin III positive cells in the noggin-treated group and $39.4 \pm 2.1 \%$ in the noggin-free group (Figs. $3 \mathrm{~A}$ and $3 \mathrm{~B}$ ). Rates of NSE and NeuN expression in the bFGF withdrawal+RA group were $56.3 \pm 4.2 \%$ and $53.5 \pm 6.6 \%$ in noggin-treated cultures, not significantly different from the bFGF maintenance group. Similar rates of NSE and NeuN expression in bFGF withdrawal+RA and bFGFmaintenance group were also observed in the noggin-free group (data not shown). These results showed that treatment with RA and bFGF maintenance have the same effects on expression of neuronal markers.

\section{The highest level of neural markers expression is achieved by a combination of RA and bFGF} Combined treatment with bFGF and RA (bFGF maintenance+RA) showed the highest level of $\beta$-tubulin III expression in all treatment groups (at day $21,70.4 \pm 3 \%$ in the noggin group and $47.6 \pm 2.5 \%$ in the noggin-free group). At day 21, the differences between bFGF maintenance $+\mathrm{RA}$ group and the other treatments (bFGF withdrawal, bFGF maintenance and bFGF withdrawal+RA) were significant. The significance levels are shown in Figs. 3A and 3B. Investigation of other neuronal markers also confirms that combined treatment with $\mathrm{bFGF}$ and RA has the highest potency related to other groups. At day $21,72.4 \pm 5.8 \%$ and $76 \pm 6.9 \%$ of cells in noggin treated cultures were positive for NSE and NeuN, respectively.

\section{Pretreatment with noggin increases expression of neural markers}

To investigate whether attenuation of BMP signaling induces neural differentiation of AECs, half of the cultures were supplemented with noggin for 7 days prior to $\mathrm{bFGF}$ withdrawal. To compare the effects of noggin pretreatment on neuronal markers expression, the similar treatment groups were compared with each other between noggin treated group and noggin free group. All treated cultures in noggin-treated group showed significantly the higher levels of $\beta$-tubulin III, NSE and NeuN antibodies positive cells compared to similar treated cultures in the noggin free group in all days of examination $(P<0.01)$ (Figures $3 \mathrm{C}-3 \mathrm{H})$. In contrast to the high rate of neural differentiation, very few cells expressed endodermal marker (GATA-6; $5.3 \% \pm 3.1 \%$ ) or mesodermal marker (brachyury; $4.7 \pm 3.8 \%$ ) in the noggin treated cultures (Figures 3I-3L). On the other hand, absence of noggin in the cultures decreased neural markers and conversely increased other lineage markers. At day 21, in the noggin free group $18.2 \pm 4.6$ and $20.8 \pm 4.2 \%$ of cells were positive for GATA-6 and brachyury, respectively (Data are belong to bFGF maintenance+RA groups). Since the used cells in this study have epithelial nature and noggin inhibits formation of tissue of epithelial origin, we investigated the pan-cytokeratin marker after differentiation of AECs to neural cells. The results in both noggin free and noggin treated cultures showed pan-cytokeratin expression decreased after 21 days, but more noticeable reduction was observed in noggin treated group. At day 21, rates of pancytokeratin positive cells for bFGF maintenance + RA were $34.2 \pm 8.6 \%$ in noggin free cultures versus $8.4 \pm 5.9 \%$ in noggin treated cultures. 
Table 1: the effects of serum and ITS on viability of AECs at D0.

\begin{tabular}{|c|c|c|c|c|}
\hline Treatment & Serum 10\% & Serum-free & $\begin{array}{c}\text { Serum-free }+ \\
\text { ITS 1\% }\end{array}$ & $\begin{array}{c}\text { Serum 1\%+ } \\
\text { ITS 1\% }\end{array}$ \\
\hline Viability (\%) & $93 \pm 3.3$ & $18 \pm 7.5$ & $68 \pm 6.3$ & $90 \pm 5.5$ \\
\hline
\end{tabular}

\section{The serum prevents expression of neural markers in} AECs

Since it has been shown that the serum prevents neural differentiation (Kawasaki et al., 2000), the serum was decreased in the medium. At first, the serum was completely omitted from the medium. Complete omission of the serum declines the cell viability to less than $20 \%$ at D0. Then, we added ITS 1\% to medium. Although addition of ITS $1 \%$ increased the cell viability, the difference was significant in comparison to presence of the serum. Therefore the serum $1 \%$ was added to medium and reduction of serum from $10 \%$ to $1 \%$ was used as an inducer of differentiation. The effects of the serum on the viability of the cells at D0 have been summarized in Table 1 .

Then, we tested whether the serum affects on expression of neural markers in AECs as occurred in ESCs. The serum was decreased to $1 \%$ and ITS $1 \%$ was added in the half of the cultures and the rates of $\beta$-tubulin III, NSE and NeuN expression was compared to the cultures with serum $10 \%$. The protocol bFGF maintenance+RA with noggin pretreatment was used for differentiation as mentioned previously. As shown in figure 4, at days 14 and 21 , the serum decreased the rate of $\beta$-tubulin III expression and the differences between the serum $10 \%$ group and the serum 1\%+ ITS 1\% group were significant. Rates of $\beta$-tubulin III expression in the serum $10 \%$ group were $51.5 \pm 3.8 \%$ and $61.8 \pm 4.7 \%$ for D14 and D21, respectively. Similarly, at day 21 , the numbers of $\mathrm{NSE}^{+}$ and $\mathrm{NeuN}^{+}$cells in the $10 \%$ serum group were $59.3 \pm 6.1 \%$ and $57.7 \pm 5.8 \%$, significantly different from the serum $1 \%$ + ITS $1 \% \operatorname{group}(P<0.01)$ (presented data in the serum $1 \%+$ ITS $1 \%$ group belong to bFGF maintenance+RA with noggin pretreatment).

\section{Discussion}

AECs are a valid alternative source for ESCs with less limitation concerns. Although some characteristics of AECs such as synthesis and release of growth factors and catecholamines have provoked researchers to employ direct transplantation of these cells (without differentiation) (Kakishita et al., 2003; Okawa et al., 2001; Nakajima et al., 2001; Elwan and Sakuragawa, 1997), to achieve desired and particular results, differentiation of AECs to specific lineages is the first necessity for their application (Niknejad et al., 2008: Ilancheran et al., 2007; Miki et al., 2005). The first aim of this paper was to investigate the effect of blocking of BMP signaling on neuronal differentiation of AECs. The results of the current research indicate that treatment of cultured AECs with noggin effectively promotes neuronal marker expression. On the other hand, addition of noggin to the culture medium clearly decreased endodermal and mesodermal marker expression and down-regulated epithelial markers. As mentioned, BMP signaling activation in undifferentiated cells can result in extraembryonic endoderm committed cells and epidermogenesis (Pera et al., 2004; Sasai et al., 1995; Wilson and Hemmati-Brivanlou, 1995). In addition, it has been reported that BMP4 can induce mesodermal differentiation (Kawasaki et al., 2000). Noggin is a wellcharacterized BMP2 and BMP4 antagonist and has been shown as neural inducer in Xenopus embryos (Gerrard et al., 2005). Since AECs are pluripotent and can give rise to all three germ layers, noggin-induced neural differentiation in this study may be achieved because of its inhibitory effects on the mesodermal, endodermal, and epidermal fate of AECs. Therefore, further investigation will be necessary to evaluate signaling pathways of BMP in AECs and the effect of noggin on inhibition of this signaling.

These results indicate that bFGF is a prominent factor for neural differentiation of AECs. bFGF is mitogenic, and can act as a differentiation and survival factor for neurons (Lee et al., 2000; Park et al., 2004). On the other hand, it has been shown that bFGF withdrawal enriches neural cells in a neural differentiation protocol (Kuo et al., 2003). The results of the current research indicate that bFGF withdrawal during this stage results in a low frequency expression of neural markers in the cells. Since removal of bFGF did not decrease the viability of cells (data not shown), it seems that bFGF acts as a differentiation factor rather than a survival factor for AECs.

EGF is another mitogenic and survival factor with several roles in the development of the mammalian CNS (Wong and Guillaud, 2004). As mentioned in some studies, EGF withdrawal has been used as an inducer of neuronal cells from stem cells (Sievertzon et al., 2005). Based on our study, EGF is a critical factor for survival of AECs. This is likely because of the epithelial origin of these cells, as similar results have been reported on the necessity of EGF for culture of AECs (Miki et al., 2005).

Using this protocol, the number of cells expressing neural markers was significantly increased by RA treatment. As mentioned, RA applied to ESCs induced concentration-dependent differentiation of neural cells. In previous studies, the high dose of RA $(50 \mu \mathrm{M})$ has been used to investigate neural differentiation of AECs (Ilancheran et al., 2007; Miki et al., 2005). Although higher doses of RA can produce a high percentage of neural cells, RA is a strong teratogen and should therefore be used at lower doses to prevent toxicity (Guan et al., 2001). In this study, a lower dose $(1 \mu \mathrm{M})$ of RA was used to induce neural marker expression in the cells. However, it should be mentioned that also $1 \mu \mathrm{M}$ of RA is a supraphysiological dose and its toxic effects on AECs remain to be studied. 
Concomitant treatment of cells with RA and bFGF produced the highest level of neural marker expression. This may be because of the additive neurogenic effects of the two growth factors, but it is in contrast to opposing effects of bFGF and RA in vivo. It has been shown that in spinal cord development in the chick embryo, FGFs blocks expression of class I HD/bHLH transcription factors and sonic hedgehog and, hence, inhibits neurogenesis. On the other hand, RA antagonizes the FGF signal and promotes neurogenesis by up-regulating class I genes (Appel and Eisen, 2003). The findings of the current study show that attenuation of FGF signaling by bFGF withdrawal does not promote expression of the used neural markers, on the contrary, its maintenance significantly increases neural marker expression. Two possible explanations exist for this observation. This may be the result of a difference between AECs and other stem cells and the induction of a different signaling pathway, or it may be due to the anti-apoptotic effect of bFGF. It has been shown that RA treatment induces apoptosis in embryonic carcinoma cells. bFGF was reported to suppress RA-associated apoptosis, possibly via the PI3K (phosphoinositide 3 kinase) pathway (Mao and Lee, 2005; Appel and Eisen, 2003). However, the interaction between bFGF and RA during neural differentiation is a challenging question and this interaction in AECs and RA-associated apoptosis at the used dose of $\mathrm{RA}$ remain to be clarified.

In the present study, the effect of serum on expression of neural markers was examined. It has been shown that serum inhibits differentiation of neuronal cells from ESCs (Kawasaki et al., 2000). On the other hand, serum enhances the potential sanitary risks due to viruses, prions or mycoplasma contaminations. Therefore, a serum-free condition for the differentiation of ESCs is desirable. ITS is an alternative for serum in the serum-free condition. Insulin is a hormone that promotes glucose and amino acid uptake by the cells. Transferrin is an iron transport protein that functions to transport iron into the cells and acts as a detoxifying protein by removing metals from the medium. Selenium is an enzyme cofactor that activates glutathione peroxidase, a player in the detoxification of oxygen radicals (George et al., 2008). In this study, although ITS was added to cultures, the viability of cells was decreased under completely serum-free conditions. Hence, $1 \%$ serum was added to the cultures. Since the serum decreased the rates of neural markers in AECs, it is essential to remove the serum from the medium completely, may be by the use of other serum replacements that are available from commercial sources.

Based on these results, AECs have the ability to express neural cell markers and this ability is affected by different growth factors. However, further investigation will be necessary to optimize conditions for neural differentiation of AECs. In addition, further studies of other neural markers and functional states will be essential to confirm the neural characteristics of these cells.

\section{Acknowledgments}

This study was a collaboratory research between the Nanomedicine and Tissue Engineering Research Center and the Neuroscience Research Center of Shaheed Beheshti Medical University and was supported by both centers. We would like to thank R. Mousavizadeh and B.J. Nooshin, for their critical comments. We are also grateful to Jaclyn Schwarz for her comments.

\section{References}

Appel B, Eisen JS (2003) Retinoids run rampant: multiple roles during spinal cord and motor neuron development. Neuron 40: 461-464.

Dono R, Texido G, Dussel R, Ehmke H. Zeller R (1998) Impaired cerebral cortex development and blood pressure regulation in FGF-2-deficient mice. EMBO J 17: 42134225.

Elwan MA, Sakuragawa N (1997) Evidence for synthesis and release of catecholamines by human amniotic epithelial cells. Neuroreport 8: 3435-3438.

George F, Daniaux C, Genicot G, Verhaeghe B, Lambert P, Donnay I (2008) Set up of a serum-free culture system for bovine embryos: embryo development and quality before and after transient transfer. Theriogenology 15: 612623.

Gerrard L, Rodgers L, Cui W (2005) Differentiation of human embryonic stem cells to neural lineages in adherent culture by blocking bone morphogenetic protein signaling. Stem Cells 23: 1234-1241.

Guan K, Chang H, Rolletschek A, Wobus AM (2001) Embryonic stem cell-derived neurogenesis. Retinoic acid induction and lineage selection of neuronal cells. Cell Tissue Res 305: 171-176.

Hopkinson A, Shanmuganathan VA, Gray T, Yeung AM, Lowe J, James DK, Dua HS (2008) Optimization of amniotic membrane (AM) denuding for tissue engineering. Tissue Eng Part C Methods 14: 371-381.

Ilancheran S, Michalska A, Peh G, Wallace EM, Pera M, Manuelpillai U (2007) Stem cells derived from human fetal membranes display multilineage differentiation potential. Biol Reprod 77: 577-588.

Kakishita K, Nakao N, Sakuragawa N, Itakura T (2003) Implantation of human amniotic epithelial cells prevents the degeneration of nigral dopamine neurons in rats with 6-hydroxydopamine lesions. Brain Res 980: 48-56.

Kawasaki H, Mizuseki K, Nishikawa S, Kaneko S, Kuwana Y, Nakanishi S, Nishikawa SI, Sasai Y (2000) Induction of midbrain dopaminergic neurons from ES cells by stromal cell-derived inducing activity. Neuron 28: 31 40.

Kuo HC, Pau KY, Yeoman RR, Mitalipov SM, Okano H, Wolf DP (2003) Differentiation of monkey embryonic stem cells into neural lineages. Biol Reprod 68: 1727-1735.

Lee SH, Lumelsky N, Studer L, Auerbach JM, McKay RD (2000) Efficient generation of midbrain and hindbrain 
neurons from mouse embryonic stem cells. Nat Biotech 18: $675-679$.

Maden M, Holder N (1992) Retinoic acid and development of the central nervous system. Bioessays 14: 431-438.

Mao Y, Lee AW (2005) A novel role for Gab2 in bFGFmediated cell survival during retinoic acid-induced neuronal differentiation. J Cell Biol 170: 305-316.

Miki T, Lehmann T, Cai H, Stolz DB, Strom SC (2005) Stem cell characteristics of amniotic epithelial cells. Stem Cells 23: 1549-1559.

Miki T, Mitamura K, Ross MA, Stolz DB, Strom SC (2007) Identification of stem cell marker-positive cells by immunofluorescence in term human amnion. J Reprod Immunol 75: 91-96.

Miyamoto K, Hayashi K, Suzuki T, Ichihara S, Yamada T, Kano Y, Yamabe T, Ito Y (2004) Human placenta feeder layers support undifferentiated growth of primate embryonic stem cells. Stem Cells 22: 433-440.

Nakajima T, Enosawa S, Mitani T, Li XK, Suzuki S, Amemiya H, Koiwai O, Sakuragawa N (2001) Cytological examination of rat amniotic epithelial cells and cell transplantation to the liver. Cell Transplant 10: 423-427.

Niknejad H, Peirovi H, Jorjani M, Ahmadiani A, Ghanavi J, Seifalian AM (2008) Properties of the amniotic membrane for potential use in tissue engineering. Eur Cell Mater 15: 88-99.

Okawa H, Okuda O, Arai H, Sakuragawa N, Sato k (2001) Amniotic epithelial cells transform into neuron-like cells in the ischemic brain. Neuroreport 12: 4003-4007.

Park S, Lee KS, Lee YJ, Shin HA, Cho HY, Wang KC, Kim YS, Lee HT, Chung KS, Kim EY, Lim J (2004) Generation of dopaminergic neurons in vitro from human embryonic stem cells treated with neurotrophic factors. Neurosci Lett 359: 99-103.

Pera MF, Andrade J, Houssami S, Reubinoff B, Trounson A, Stanley EG, Oostwaard DW, Mummery C (2004) Regulation of human embryonic stem cell differentiation by BMP-2 and its antagonist noggin. J Cell Sci 117: 1269-1280.

Sasai Y, Lu B, Steinbeisser H, De Robertis EM (1995) Regulation of neural induction by the Chd and Bmp-4 antagonistic patterning signals in Xenopus. Nature 376: 333-336.

Sievertzon M, Wirta V, Mercer A, Frisen J, Lundeberg J (2005) Epidermal growth factor (EGF) withdrawal masks gene expression differences in the study of pituitary adenylate cyclase-activating polypeptide (PACAP) activation of primary neural stem cell proliferation. BMC Neurosci 6: 55.

Tropepe V, Hitoshi S, Sirard C, Mak TW, Rossant J, Van der Kooy D (2001) Direct neural fate specification from embryonic stem cells: a primitive mammalian neural stem cell stage acquired through a default mechanism. Neuron 30: 65-78.

Wilson PA, Hemmati-Brivanlou A (1995) Induction of epidermis and inhibition of neural fate by Bmp-4. Nature 376: 331-333.

Wong RW, Guillaud L (2004) The role of epidermal growth factor and its receptors in mammalian CNS. Cytokine Growth Factor Rev 15 (2-3): 147-156.

Ying QL, Stavridis M, Griffiths D, Li M, Smith A (2003) Conversion of embryonic stem cells into neuroectodermal precursors in adherent monoculture. Nat Biotechnol 21: 183-186. 